\title{
Epratuzumab targeting of CD22 affects adhesion molecule expression and migration of B-cells in systemic lupus erythematosus
}

Capucine Daridon ${ }^{1,2^{*} \dagger}$, Daniela Blassfeld ${ }^{1 \dagger}$, Karin Reiter ${ }^{1}$, Henrik E Mei ${ }^{1,2}$, Claudia Giesecke ${ }^{1}$, David M Goldenberg ${ }^{3}$, Arne Hansen ${ }^{1}$, Arwed Hostmann ${ }^{1}$, Daniela Frölich', Thomas Dörner ${ }^{1,2}$

\begin{abstract}
Introduction: Epratuzumab, a humanized anti-CD22 monoclonal antibody, is under investigation as a therapeutic antibody in non-Hodgkin's lymphoma and systemic lupus erythematosus (SLE), but its mechanism of action on B-cells remains elusive. Treatment of SLE patients with epratuzumab leads to a reduction of circulating CD27 $7^{\text {negative }}$ B-cells, although epratuzumab is weakly cytotoxic to B-cells in vitro. Therefore, potential effects of epratuzumab on adhesion molecule expression and the migration of B-cells have been evaluated.

Methods: Epratuzumab binding specificity and the surface expression of adhesion molecules (CD62L, $\beta 7$ integrin and $\beta 1$ integrin) after culture with epratuzumab was studied on B-cell subsets of SLE patients by flow cytometry. In addition, in vitro transwell migration assays were performed to analyze the effects of epratuzumab on migration towards different chemokines such as CXCL12, CXCL13 or to CXCR3 ligands, and to assess the functional consequences of altered adhesion molecule expression.

Results: Epratuzumab binding was considerably higher on B-cells relative to other cell types assessed. No binding of epratuzumab was observed on T-cells, while weak non-specific binding of epratuzumab on monocytes was noted. On B-cells, binding of epratuzumab was particularly enhanced on CD27 negative B-cells compared to CD27 ${ }^{\text {positive }}$ B-cells, primarily related to a higher expression of CD22 on CD27 $7^{\text {negative }}$ B-cells. Moreover, epratuzumab binding led to a decrease in the cell surface expression of CD62L and $\beta 7$ integrin, while the expression of $\beta 1$ integrin was enhanced. The effects on the pattern of adhesion molecule expression observed with epratuzumab were principally confined to a fraction of the $C D 27^{\text {negative }}$ B-cell subpopulation and were associated with enhanced spontaneous migration of B-cells. Furthermore, epratuzumab also enhanced the migration of CD27 ${ }^{\text {negative }}$ B-cells towards the chemokine CXCL12.
\end{abstract}

Conclusions: The current data suggest that epratuzumab has effects on the expression of the adhesion molecules CD62L, $\beta 7$ integrin and $\beta 1$ integrin as well as on migration towards CXCL12, primarily of CD27 ${ }^{\text {negative }}$ B-cells. Therefore, induced changes in migration appear to be part of the mechanism of action of epratuzumab and are consistent with the observation that $C D 27^{\text {negative }}$ B-cells were found to be preferentially reduced in the peripheral blood under treatment.

\section{Introduction}

Systemic lupus erythematosus (SLE) is a very heterogeneous autoimmune disease with various clinical manifestations and different immune abnormalities, including

\footnotetext{
* Correspondence: daridon@drfz.de

† Contributed equally

${ }^{1}$ Charite - Universitätsmedizin Berlin, CC12 Dept. Medicine/Rheumatology and Clinical Immunology, Chariteplatz 1, Berlin 10117, Germany

Full list of author information is available at the end of the article
}

the production of a plethora of autoantibodies, deposition of immune complexes in various organs, and potential organ failure [1]. In patients with SLE, disturbances of B-cells in the peripheral blood (including an increase of $\mathrm{CD} 27^{\text {negative }}$ transitional $\mathrm{B}$-cells and $\mathrm{CD} 27^{\text {positive }}$ B-cells as well as enhanced CD27 ${ }^{\text {high }}$ plasmablasts), abnormalities of humoral immunity, immune complex formation, complement activation as well as experiences

\section{Biomed Central}


in clinical trials with B-cell directed therapy, suggest a key role for B-cells in the pathogenesis of this disease. Hence, immunotherapy targeting B-cells is currently of great interest with the promise to improve current treatments of SLE. In this context, epratuzumab, a humanized monoclonal $\mathrm{IgG}_{1}$ antibody (mAb) that targets the B-cell surface molecule CD22, has been explored in an early clinical trial [2] and more recently in a phase IIb randomized clinical study which showed a treatment advantage with epratuzumab over placebo of around $25 \%$ at week 12 [3].

CD22, a $140 \mathrm{kDa}$ transmenbrane type 1 protein, also called Sialic acid-binding Ig-like lectin 2 (Siglec-2) or B-lymphocyte cell adhesion molecule (BL-CAM), is a member of the Siglec family that binds to $\alpha 2-6$-linked sialic acids on glycoproteins. These ligands for CD22 are widely expressed on different cell types [4] (co called trans glycoprotein ligands) including B-cells (where CD22 will also bind cis glycoprotein ligands).

CD22 is differentially expressed during B-cell differentiation. At early developmental stages, such as preB-cells, CD22 is expressed intracellularly and appears on the surface on immature $B$-cells reaching the highest surface expression levels on mature B-cells and declining substantially during final maturation into plasma cells [5-7]. Although Stathish et al. also described the expression of CD22 on murine primary T-cells [8], CD22 has not been detected on human T-cells and monocytes [4].

Interestingly, CD22 has two different functions on B-cells. It is well known as a negative regulatory molecule of the B-cell antigen receptor (BCR) signal leading to inhibition of B-cell activation by phosphorylation of the protein tyrosine phosphatase SHP-1 (Src homology region 2 domain-containing phosphatase 1 ) via the immunoreceptor tyrosine-based inhibitory motifs (ITIMs) contained in the cytoplasmic tail [9]. Moreover, $\mathrm{CD} 22$ is also considered as an adhesion receptor for the homing of re-circulating $\operatorname{IgD}^{\text {positive }} \mathrm{B}$-cells in the bone marrow via the expression of CD22 ligand on bone marrow sinusoidal endothelium [10-12].

The functional diversity of CD22 has implications for the hitherto unknown mechanism of action by epratuzu$\mathrm{mab}$ and is of interest. Initial treatment with this $\mathrm{mAb}$ in patients with SLE showed a significant decrease of BILAG (British Isles Lupus Assessment Group) scores above $50 \%$ [2]. In this study, a significant reduction of peripheral B-cells was also observed in SLE patients who were treated with epratuzumab, primarily a $30 \%$ reduction of $\mathrm{CD} 27^{\text {negative }} \mathrm{B}$-cells comprising transitional and naive $B$-cells $[2,13]$. The reason for the reduction in B-cell numbers remains unknown.

In this context, earlier studies reported that epratuzumab, in contrast to rituximab, was weakly cytotoxic for
B-cells since it could induce modest antibody-dependent cellular cytotoxicity (ADCC) and no complementdependent cytotoxicity (CDC) in vitro; however, epratuzumab modulates exaggerated activation and proliferation of B-cells from SLE patients following CpG, BCR and CD40L stimulation [13-15]. Epratuzumab binds to non-ligand binding epitopes on CD22 and provokes phosphorylation of CD22 [16,17].

While epratuzumab appears to have only a very limited capacity to induce direct apoptosis $[13,14]$ via CDC and ADCC, the apparent reduction of peripheral blood $\mathrm{CD} 27^{\text {negative }} \mathrm{B}$-cells under therapy led to the hypothesis that triggering CD22 could modulate B-cell migration possibly resulting in reduced $\mathrm{CD} 27^{\text {negative }} \mathrm{B}$-cell counts in the blood. Since cell trafficking is a multistep process involving the concerted interaction of cell adhesion molecules binding to their respective ligands as well as chemokine-regulated migration pathways, our study was designed to assess the effects of epratuzumab on the expression of a range of adhesion molecules (CD62L, $\beta 1$ integrin and $\beta 7$ integrin) and migration towards CXCL12, CXCL13 and a number of CXCR3 ligands (CXCL9, 10 and 11) on peripheral blood mononuclear cells (PBMCs) from SLE patients. These three adhesion molecules and their ligands are critical for B-cell trafficking. CD62L (L-selectin) is involved in the homing of B-cells preferentially into peripheral lymphoid tissues through high endothelial venules (HEV). The $\beta 7$ integrin associated with its $\alpha 4$ integrin partner (to form the $\alpha 4 \beta 7$ integrin) is responsible for the homing of lymphocytes preferentially into mucosal immune tissues via the ligand mucosal addressin cell adhesion molecule-1 (MAdCAM-1) on large endothelial venules, while the $\alpha 4 \beta 1$ integrin, a receptor for fibronectin and vascular cell adhesion molecule-1 (VCAM-1), is preferentially involved in the homing and retention of lymphocytes and hematopoietic stem cells to the bone marrow and the trafficking of leukocytes [18-23]. Therefore, we addressed the potential influence of epratuzumab on the cell surface expression of adhesion molecules and cell migration in vitro which are important B-cell functions.

The results from the current study demonstrate specific binding of epratuzumab on B-cells. Additionally, we observed greater binding of epratuzumab on $\mathrm{CD} 27^{\text {nega- }}$ tive B-cells which was related to the expression of CD22 which was higher on CD27 $7^{\text {negative }}$ B-cells compared to $\mathrm{CD} 27^{\text {positive }}$ B-cells. Epratuzumab binding to $\mathrm{CD} 27^{\text {negative }}$ B-cells induced a significant reduction of CD62L and $\beta 7$ integrin surface expression, while $\beta 1$ integrin was upregulated. Functionally, CD $27^{\text {negative }}$ B-cells cultured with epratuzumab showed enhanced spontaneous migration across fibronectin coated filters. Finally, epratuzumab incubation was found to enhance the migration towards CXCL12 of CD27 $7^{\text {negative }}$ B-cells, but not of 
CD27 ${ }^{\text {positive }}$ B-cells. These results suggest that epratuzumab is able to modulate B-cell migration and adhesion molecule expression, processes that potentially contribute to its mechanism of action in SLE.

\section{Materials and methods Subjects}

After informed consent was obtained for the protocol approved by the Institutional Review Board at the Charité - University Hospitals, Berlin, SLE patients were enrolled in the study. All patients fulfilled the American College of Rheumatology ACR criteria, revised in 1982 [24]. Thirty SLE patients (28 females, 2 males), $39.1 \pm$ 13.9 years old were studied. PBMCs were prepared from 30 to $40 \mathrm{~mL}$ anti-coagulated blood by density gradient centrifugation over ficoll-paque (Amersham Pharmacia Biotech, Uppsala, Sweden), and then washed twice with phosphate-buffered saline (PBS) supplemented with $0.05 \%(w / v)$ of bovine serum albumin (BSA, SigmaAldrich, Seelze, Germany).

\section{Adhesion molecule surface expression after epratuzumab incubation}

To monitor changes of adhesion molecule surface expression ( $\beta 1$ integrin, $\beta 7$ integrin and CD62L) after epratuzumab incubation, freshly isolated PBMCs were incubated with $10 \mu \mathrm{g} / \mathrm{mL}$ of epratuzumab in RPMI 1640 medium (Gibco BRL, Karlsruhe, Germany) supplemented with $0.5 \%(\mathrm{w} / \mathrm{v}) \mathrm{BSA}$ for 90 minutes at $37^{\circ} \mathrm{C}$ and $5 \%$ $\mathrm{CO}_{2}$. After incubation, the PBMCs were washed in cold PBS-BSA $0.05 \%(\mathrm{w} / \mathrm{v})$ and then stained on ice for FACS analysis as described below.

\section{Fibronectin-dependent chemotaxis}

Fibronectin-dependent chemotaxis was assessed using transwell migration plates $(5.0 \mu \mathrm{m}$ pores, Corning Life Sciences, Acton, MA, USA) coated with $10 \mu \mathrm{g} / \mathrm{mL}$ of fibronectin (Invitrogen, Carlsbad, CA, USA), a ligand for the $\beta 1$ integrin [25].

$1 \times 10^{6}$ PBMCs were incubated with or without 10 $\mu \mathrm{g} / \mathrm{mL}$ of epratuzumab and allowed to migrate for 90 minutes at $37^{\circ} \mathrm{C}$ and $5 \% \mathrm{CO}_{2}$ using transwell migration assays. Migration towards CXCL12 (50 nM) (stromal cell-derived factor, SDF1) or CXCL13 (250 nM) (B-cell homing chemokine, BLC or also B-cell attracting chemokine 1, BCA1) or to a mix of CXCR3 ligands (CXCL9 (250 nM) (monokine induced by gamma interferon, MIG), CXCL10 (300 nM) (interferon inducible protein 10, IP10) and CXCL11 (10 nM) (interferoninducible $\mathrm{T}$-cell alpha chemoattractant, I-TAC)) were studied by adding the different chemokines to the lower chamber in RPMI 1640 supplemented with 0.5\% (w/v) BSA as described previously [26]. All chemokines were from R\&D Systems, Minneapolis, MN, USA.
At the end of the incubation, migrated and nonmigrated cells were harvested from the lower and upper compartments, respectively, counted and phenotyped by FACS as described below. The results were expressed as percentage of migrated B-cells using the following formula: number of migrated B-cells/(number of non migrated B-cells + number of migrated B-cells $) \times 100$.

To assess spontaneous migration, controlled migrations were performed without using any chemokine gradient. The B-cells that migrated independently of the chemokine gradient were considered to have functional $\beta 1$ integrin.

\section{FACS analysis}

Staining of freshly isolated PBMCs and treated PBMCs was performed as described previously [26]. The following antibodies were used: CD3-Pacific Blue (PB) or H7-allophycocyanin (APC) (BD, Clone UCHT1), CD14-PB or H7-APC (BD, Clone m5e2), CD19-phycoerythrin-cyanin 7 (PE-Cy7) (BD, Clone SJ 25C1), $\mathrm{CD} 20$-peridin chlorophyll protein (PerCP) (BD, Clone L27), CD62L-fluorescein isothiocyanate (FITC) (Clone 145/15, Miltenyi Biotec, Auburn, CA, USA), CD27cyanin 5 (Cy5) (clone 2E4, kindly provided by Rene Van Lier, University of Amsterdam, The Netherlands), $\beta 7$ integrin-phycoerythrin (PE) (BD, clone FIB504), $\beta 1$ integrin-PE (BD, clone MAR4), CD22-PE (BD, clone $\mathrm{S}-\mathrm{HCL}-1)$ and epratuzumab IgG and $\left.\mathrm{F}(\mathrm{ab})_{2}\right)_{2}$ fragment of epratuzumab (provided by UCB, Slough, UK). $\mathrm{T}$-cells, B-cells and monocytes were gated using their scatter properties and stained for CD3, CD19 or CD14. Analysis was performed with a Becton Dickinson Canto II machine and data were analyzed using FCS Express 3.0 software (DeNovo Software, Los Angeles, CA, USA) or using FlowJo ${ }^{\mathrm{m}}$ software (TreeStar, Ashland, OR, USA).

\section{Binding specificity of epratuzumab experiments}

A total of 1 to $2 \times 10^{6}$ freshly isolated PBMCs were preincubated in $50 \mu \mathrm{l}$ of PBS/0.05\% (w/v) BSA with or without $8.8 \mu \mathrm{g}$ of unlabeled $\mathrm{F}(\mathrm{ab})_{2}$ fragment of epratuzumab for 10 minutes on ice, then $1 \mu \mathrm{g}$ of PE-labeled epratuzumab, CD3/14 H7-APC, CD27-Cy5, CD20PerCP and CD19-PE-Cy7 were added to the PBMCs. After 15 minutes of staining in the dark, the PBMCs were washed two times in cold PBS/0.05\% (w/v) BSA and then analyzed by FACS.

\section{Statistical analysis}

Unpaired data sets were compared using the nonparametric Mann-Whitney U-test and paired data were analyzed using the Wilcoxon test with GraphPad Prism4 software (GraphPad, San Diego, CA, USA). A P-value less than 0.05 was considered significant (* $P<0.05$; 
$\left.{ }^{* *} P<0.01 ; * * P<0.001\right)$. All values are expressed as mean \pm standard deviation unless otherwise specified.

\section{Results}

Enhanced CD22 expression and epratuzumab binding to CD27 ${ }^{\text {negative }} B$-cells from SLE patients

In order to delineate more thoroughly the effects of epratuzumab in relation to its target CD22, the binding capacity of epratuzumab to specific leukocyte subsets such as T-cells, B-cells and monocytes was studied. Therefore, FACS analyses were performed on PBMCs from SLE patients with PE-labelled epratuzumab. Clear binding of epratuzumab on B-cells was shown, whereas no epratuzumab binding was observed on T-cells. Interestingly, epratuzumab appeared to bind to monocytes (Figure 1a). To further evaluate the binding specificities of epratuzumab, we performed blocking experiments where cells were incubated with unlabeled $\mathrm{F}(\mathrm{ab})_{2}$ fragments of epratuzumab for 10 minutes on ice (Figure 1b, grey histogram) and then stained with PE-labeled epratuzumab (Figure 1b, black line histogram). We observed inhibition of epratuzumab binding after incubation with unlabeled $F\left(a b^{\prime}\right)_{2}$ fragments of epratuzumab on B-cells (Figure 1b, left graph). From these experiments, we conclude that epratuzumab binds specifically to B-cells via CD22 without a requirement for $\mathrm{Fc}$ fragment binding. $\mathrm{T}$-cells did not show any epratuzumab binding and were subsequently used as negative control. Notably, we did not observe any significant inhibition of epratuzumab binding on monocytes after incubation with unlabeled $F(a b)_{2}$ fragment of epratuzumab (Figure 1b), suggesting that the binding of this antibody to monocytes is likely related to the Fc moiety. Furthermore, experiments with a commercially available mouse anti-human CD22 antibody, clone S-HCL-1, targeting a different epitope on CD22 than epratuzumab [16] did not show any binding to either monocytes or $\mathrm{T}$ cells (data not shown).
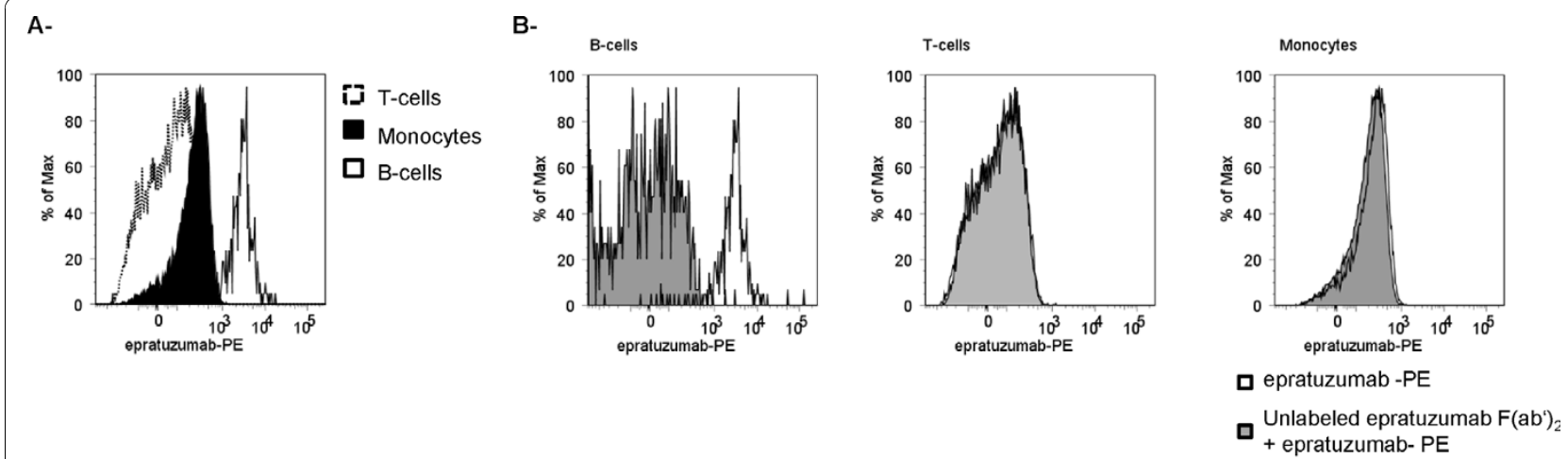

C-
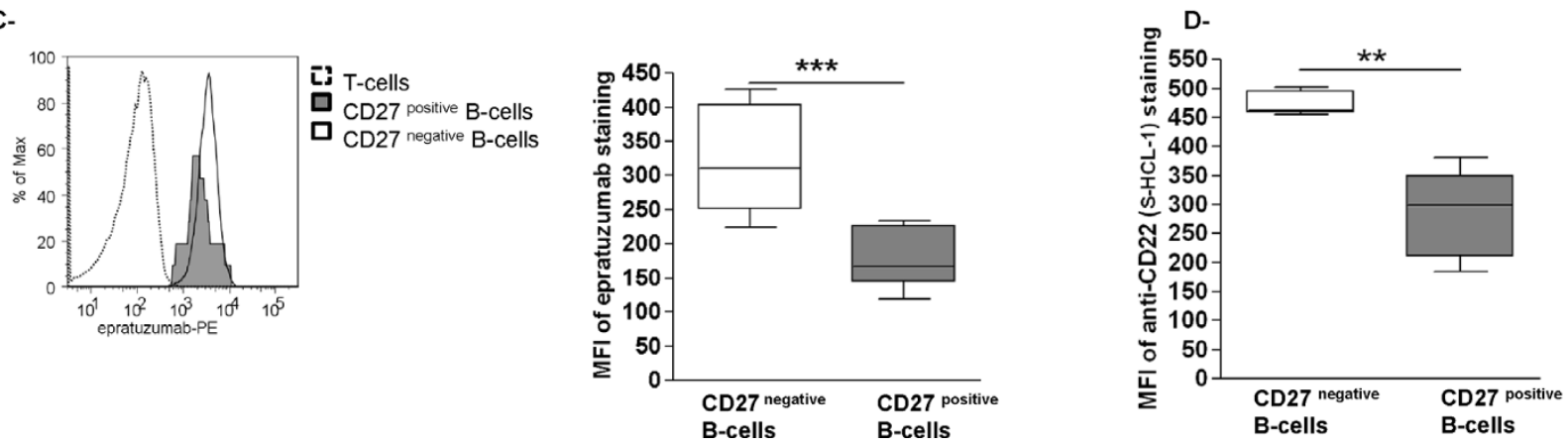

Figure 1 The binding capacity of epratuzumab on different PBMCs obtained from SLE patients. (a) FACS analyses were performed on PBMCs from SLE patients using PE- labeled epratuzumab. Representative histogram of the differential binding of epratuzumab on T-cells $\left(C D 3^{\text {positive }}\right.$, dotted line), monocytes $\left(C D 14^{\text {positive }}\right.$, black histogram) and B-cells (CD19 ${ }^{\text {positive }}$, black line). (b) PBMCs were incubated with (grey histogram) or without (black line) unlabelled $\mathrm{F}\left(\mathrm{ab}^{\prime}\right)_{2}$ epratuzumab fragment for 10 minutes at $4^{\circ} \mathrm{C}$. PBMCs were then stained with PE labeledepratuzumab, and epratuzumab binding analyzed on B-cells, T-cells and monocytes $(n=3)$. Representative histogram of epratuzumab binding on B-cell sub-populations: CD27 ${ }^{\text {negative }}$ B-cells (black line), CD27 $7^{\text {positive }}$ B-cells (grey histogram) and T-cells (negative control, dotted line) are shown in (c). The results of the FACS analysis (right graph), showed higher binding capacity of epratuzumab on CD27 ${ }^{\text {negative }}$ B-cells compare to CD27 ${ }^{\text {positive }}$ B-cells $(P=0.0002)$. (d) To study the expression of CD22 on B-cells, PBMCs were stained with a mouse anti-CD22 mAb (Clone S-HCL-1), which recognizes a different epitope than epratuzumab $(n=5)$ [16]. The FACS analysis demonstrated that CD22 is more highly expressed on CD27 $7^{\text {negative }}$ B-cells compared to CD27 $7^{\text {positive }}$ B-cells. 
These results confirmed the absence of surface expression of CD22 on T-cells and monocytes as described by others [4].

Subsequent studies focused in detail on the effects induced by epratuzumab on particular B-cell subpopulations. Initially, we studied the expression of CD22 on B cell subsets based on their expression of CD27, the $\mathrm{CD} 27^{\text {negative }} \mathrm{B}$-cell subpopulation comprising naïve and transitional B-cells and the $\mathrm{CD} 27^{\text {positive }} \mathrm{B}$-cells comprising pre- $\left(\operatorname{IgD}^{+}\right)$and post-switch $\left(\operatorname{IgD}^{-}\right)$memory B-cells [13].

In this analysis, a substantially higher binding of epratuzumab on $\mathrm{CD} 27^{\text {negative }} \mathrm{B}$-cells versus $\mathrm{CD} 27^{\text {positive }}$ B-cells was observed as shown by a representative histogram in Figure 1c. In fact, there was a two-fold enhanced anti-CD22 binding to CD27 ${ }^{\text {negative }}$ B-cells (mean fluorescence intensity (MFI) $324.7 \pm 74.4$ ) compared to CD27 $7^{\text {positive }}$ B-cells (MFI $\left.172.9 \pm 40.9\right)(P=$ 0.0002).

In order to confirm the differential expression of CD22 on B-cell subpopulations, experiments were repeated using the mouse anti-human CD22 antibody, S-HCL-1, which recognizes a different epitope to epratuzumab [16]. These experiments confirmed a higher CD22 expression on CD27 $7^{\text {negative }}$ B-cells compared to CD27 ${ }^{\text {positive }}$ B-cells (Figure $1 \mathrm{~d}, n=5$ ). In summary, specific binding of epratuzumab on the surface of B-cells has been confirmed with the highest propensity identified on $\mathrm{CD} 27^{\text {negative }}$ B-cells.

\section{Epratuzumab down-modulates CD62L and $\beta 7$ integrin surface expression on B-cells}

Subsequent studies were designed to identify whether epratuzumab binding to CD22, known to function as an adhesion molecule, could modulate the surface expression of other adhesion molecules on B-cells. Therefore, CD62L, $\beta 7$ integrin and $\beta 1$ integrin surface expression on PBMCs from SLE patients were studied in vitro after culture with epratuzumab.

First, the surface expression of CD62L, an adhesion molecule involved in systemic B-cell activation [19], on PBMCs was assessed. As shown in Figure 2a (representative of nine independent experiments using PBMCs from SLE patients), epratuzumab incubation led to a significant down-modulation of CD62L on the surface of B-cells $(P=0.0078)$. Thus, CD62L was found to be expressed on $56.7 \pm 16.4 \%$ of peripheral B-cells after incubation without epratuzumab which was reduced to $42.5 \pm 12.6 \%$ after epratuzumab incubation. Notably, around $15 \%$ of B-cells became negative for CD62L expression on their surface after epratuzumab incubation. No significant difference was observed either on peripheral T-cells or monocytes after epratuzumab incubation (Figure 2a).
Further studies demonstrated that the reduced surface expression of CD62L was restricted to CD27 $7^{\text {negative }}$ B-cells; when this subset was analyzed, $57.9 \pm 18.6 \%$ were positive for CD62L in the absence of epratuzumab (white bar, Figure $2 \mathrm{~b}$ ) and $37.9 \pm 15.5 \%$ after epratuzumab incubation (grey bar, Figure 2b) $(* * P=0.004$; Figure 2b). However, the frequency of B-cells being CD62 $\mathrm{L}^{\text {positive }}$ and $\mathrm{CD} 27^{\text {positive }}$ remained unaffected by epratuzumab $(48.7 \pm 19 \%$ versus $44 \pm 15.4 \%)$.

Additional studies on the expression of the mucosal adhesion molecule $\beta 7$ integrin on $\mathrm{CD} 27^{\text {positive }}$ and CD27 $7^{\text {negative }}$ B-cells are summarized in Figure 2c. Epratuzumab incubation induced a significant reduction of the surface expression of $\beta 7$ integrin $(P=0.0039)$, primarily confined to $\mathrm{CD} 27^{\text {negative }} \mathrm{B}$-cells, while no changes were observed on $\mathrm{CD} 27^{\text {positive }} \mathrm{B}$-cells. Of note, surface expression of CD62L and $\beta 7$ integrin was simultaneously downmodulated on B-cells after incubation with epratuzumab. The percentage of CD27 $7^{\text {negative }} \mathrm{B}$-cells expressing both CD62L and $\beta 7$ integrin was significantly decreased after epratuzumab incubation, from $44.5 \pm 16.6 \%$ to $28.1 \pm 15 \%$ (data not shown). The decrease of both CD62L and $\beta 7$ integrin on the surface of $\mathrm{CD} 27^{\text {negative }} \mathrm{B}$-cells suggests that epratuzumab has the potential to change the adhesion characteristics of this particular population.

\section{Epratuzumab incubation leads to an increase of $\beta 1$ integrin surface expression on B-cells}

Based on the observed down-modulation of $\beta 7$ integrin surface expression on CD27 $7^{\text {negative }}$ B-cells by epratuzumab, further analyses focused on the effect of epratuzumab on the expression of the $\beta 1$ integrin on the surface of B-cells. In this regard, integrin complexes are composed of $\beta$ and $\alpha$ subunits and form unique molecules, and $\beta 7$ integrin essentially competes with $\beta 1$ integrin for the same $\alpha 4$ subunit. A recent study [27] reported that the surface expression of $\alpha 4 \beta 7$ integrin is regulated in a homeostatic relation with the surface expression of $\alpha 4 \beta 1$ integrin on T-cells since high expression of $\alpha 4 \beta 1$ integrin resulted in a loss of $\alpha 4 \beta 7$ integrin. With this in mind, subsequent studies were performed to analyze whether down-modulation of $\beta 7$ integrin on the surface of the $\mathrm{CD} 27^{\text {negative }} \mathrm{B}$-cells is associated with changes in the expression of $\beta 1$ integrin. There appeared to be two populations of B-cells that, in their basal state, were either $\beta 1$ integrin $^{\text {low }}$ or $\beta 1$ integrin $^{\text {high }}$ as shown in Figure 3. In fact, the data showed that the majority of $\mathrm{CD} 27^{\text {positive }}$ B-cells expressed high basal levels of $\beta 1$ integrin on their cell surface compared with CD27 ${ }^{\text {negative }}$ B-cells (Figure 3, middle and right column). After incubation of PBMCs with epratuzumab, the percentage of B-cells that were $\beta 1$ integrin $^{\text {high }}$ increased from $17 \pm 7 \%$ to $42 \pm 10.5 \%$ (Figure 3 ). With regard to $C D 27^{\text {negative }} B$-cells, a significant change in the proportion of $\beta 1$ integrin $^{\text {high }}$ cells was observed after 


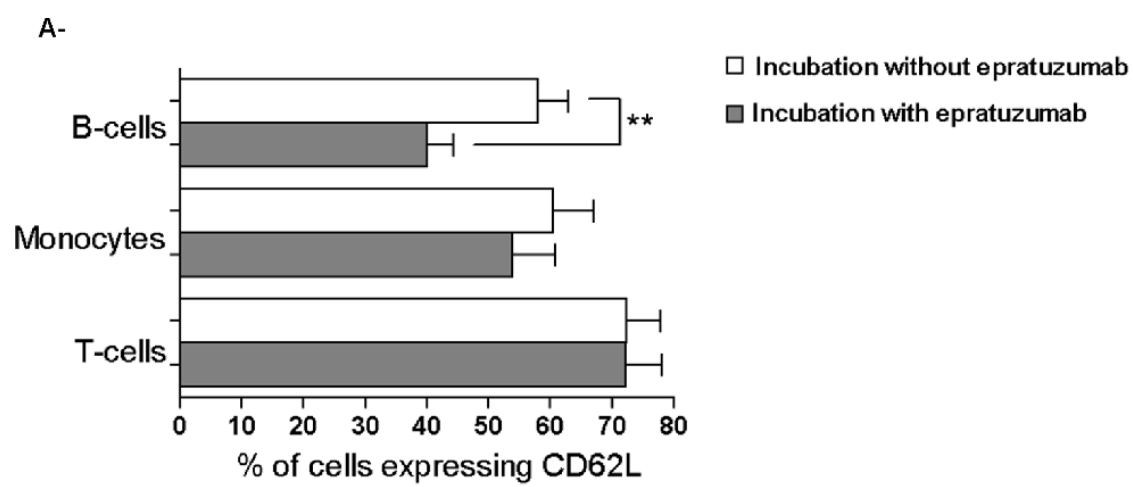

B-

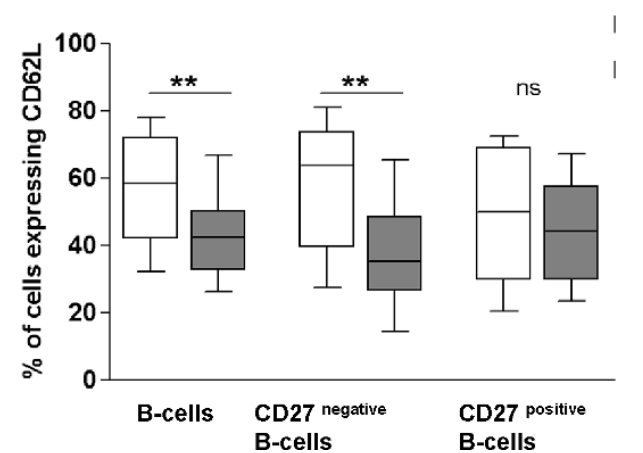

C-

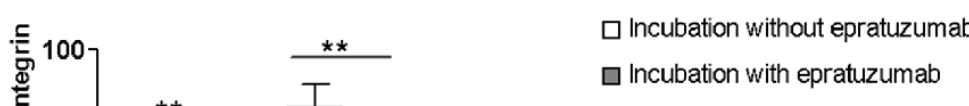

ns

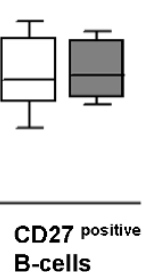

Figure 2 Epratuzumab leads to decreased surface expression of the adhesion molecules CD62L and $\beta 7$ integrin on CD27 $7^{\text {negative }} B-c e l l s$. Comparison of the surface expression of CD62L on PBMCs from SLE patients with (grey histogram) and without (white histogram) epratuzumab incubation (a). Monocytes (CD14 ${ }^{\text {positive }}$ ) showed a moderate but non-significant reduction of CD62L, whereas this expression was not influenced on T-cells (CD3 $\left.{ }^{\text {positive }}\right)$ by epratuzumab. Notably, epratuzumab led to a significant reduction of the CD62L surface expression on B-cells $(P<0.01)$. These comparative studies of CD27 ${ }^{\text {negative }}$ B-cells versus CD27 $7^{\text {positive }}$ B-cells demonstrated that the reduction of CD62L was confined to CD27 $7^{\text {negative }} B$-cells $(\mathbf{b})(P<0.01)$. Similarly, the surface expression of $\beta 7$ integrin (c) was significantly reduced by epratuzumab on $C D 27^{\text {negative }}$ B-cells but not on CD27 $7^{\text {positive }}$ B-cells (** $P<0.01$; ns not significant, $n=9$ ).

incubation with epratuzumab $(36.3 \pm 11.3 \%)$ versus a human $\operatorname{IgG}_{1}$ control $(11.4 \pm 6.3 \%)$ or without Ig (11.2 \pm $3.9 \%)$. No difference in the proportion of $\beta 1$ integrin $^{\text {high }}$ cells was observed on $\mathrm{CD} 27^{\text {positive }} \mathrm{B}$-cells after epratuzumab treatment.

Since fibronectin is one of the ligands for the $\alpha 4 \beta 1$ integrin, transwell migration assays using fibronectincoated filters were employed as functional tests for spontaneous migration. Notably, incubation of B-cells with epratuzumab provoked enhanced spontaneous transmigration of B-cells (Figure 4) which was seen for CD27 ${ }^{\text {posi- }}$ tive and CD27 ${ }^{\text {negative }} \mathrm{B}$-cells. However, the transmigration was around threefold higher for $\mathrm{CD} 27^{\text {negative }} \mathrm{B}$-cells compared to a twofold increase for $\mathrm{CD} 27^{\text {positive }} \mathrm{B}$-cells.

These data suggest that epratuzumab is able to increase $\beta 1$ integrin expression on a fraction of $\mathrm{CD} 27^{\text {negative }} \mathrm{B}$ cells and this is associated with a substantial increase in the functional activity of this integrin.

\section{Epratuzumab enhanced migration of B-cells towards} CXCL12

Additional experiments analyzed the effect of epratuzumab on the migration of $\mathrm{B}$ cells towards a range of chemokines, such as CXCL12, CXCL13 and to CXCR3 ligands. PBMCs from SLE patients were incubated with or without epratuzumab and allowed to migrate for 90 minutes at $37^{\circ} \mathrm{C}$. Notably, epratuzumab further increased the chemotactic response towards CXCL12 (Figure 5a) $(P=0.015)$ but there was no significant change in the migration towards CXCL13 or CXCR3 ligands (Figure $5 a$ ). No influence of epratuzumab was noted on monocytes or T-cells. Furthermore, epratuzumab led to a more pronounced effect on the migration towards CXCL12 on CD27 ${ }^{\text {negative }}$ B-cells compared to $\mathrm{CD} 27^{\text {posi- }}$ tive $\mathrm{B}$-cells $(P=0.0078$; Figure $5 \mathrm{~b})$. The migration capacity of both CD27 ${ }^{\text {negative }} B$-cells and CD27 $7^{\text {positive }}$ B-cells to CXCL13 and CXCR3 ligands was unaffected 


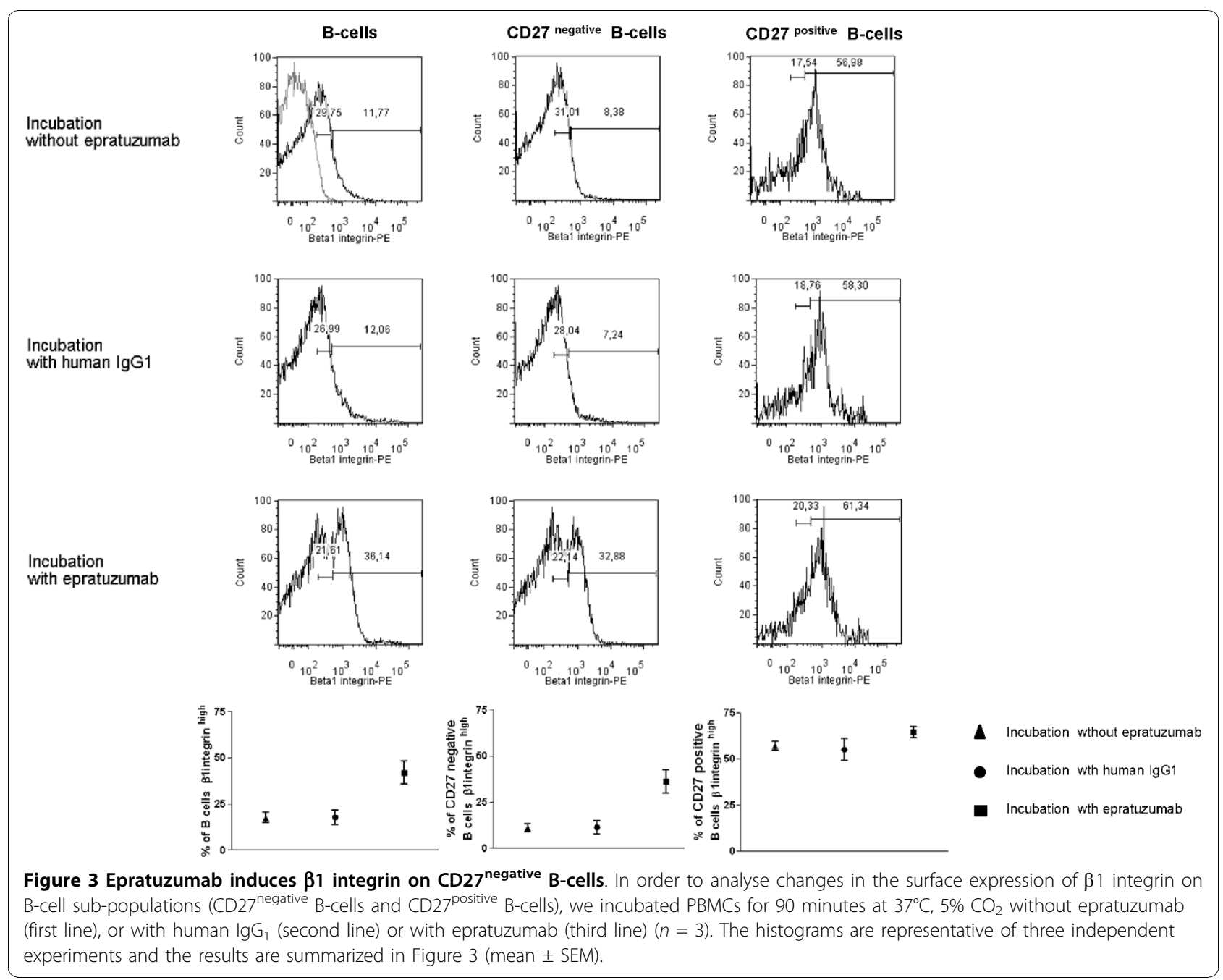

by incubation with epratuzumab (data not shown). These data indicate that another consequence of high CD22 expression on CD27 $7^{\text {negative }} \mathrm{B}$-cells is increased migration towards CXCL12 in the presence of epratuzumab.

\section{Discussion}

This study demonstrates that epratuzumab is able to induce significant functional changes on B-cells in vitro, particularly of $\mathrm{CD} 27^{\text {negative }} \mathrm{B}$-cells, which include 1 ) a substantial reduction of the cell-surface expression of
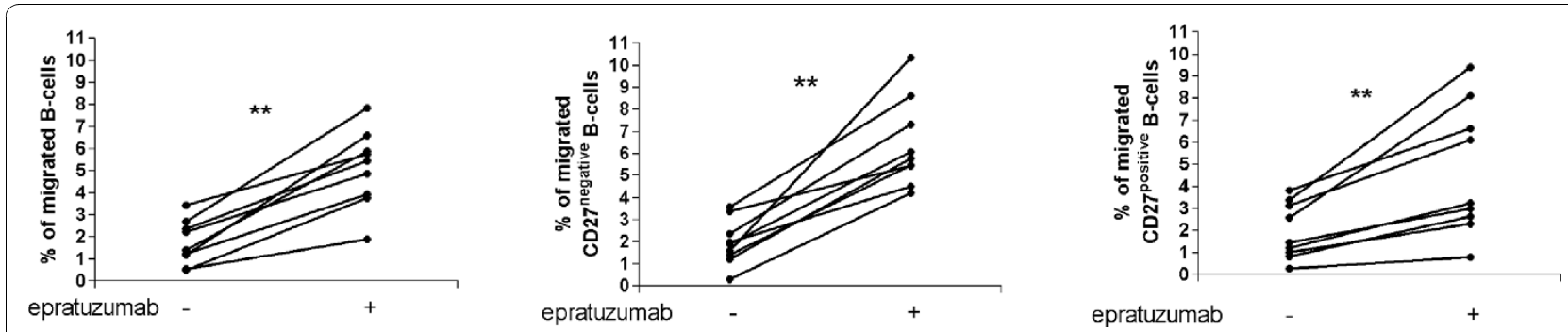

Figure 4 Epratuzumab increases the motility of the B-cells. To evaluate the functionality of $\beta 1$ integrin on the B-cells, we checked the capacity of B-cells to transmigrate through fibronectin independently of chemoattractant, with epratuzumab incubation (data from nine independent experiments are shown in Figure 4). Epratuzumab caused an enhanced transmigration through fibronection layers; indeed, a threefold greater basal motility of treated $\mathrm{CD} 27^{\text {negative }}$ B-cells was observed. 


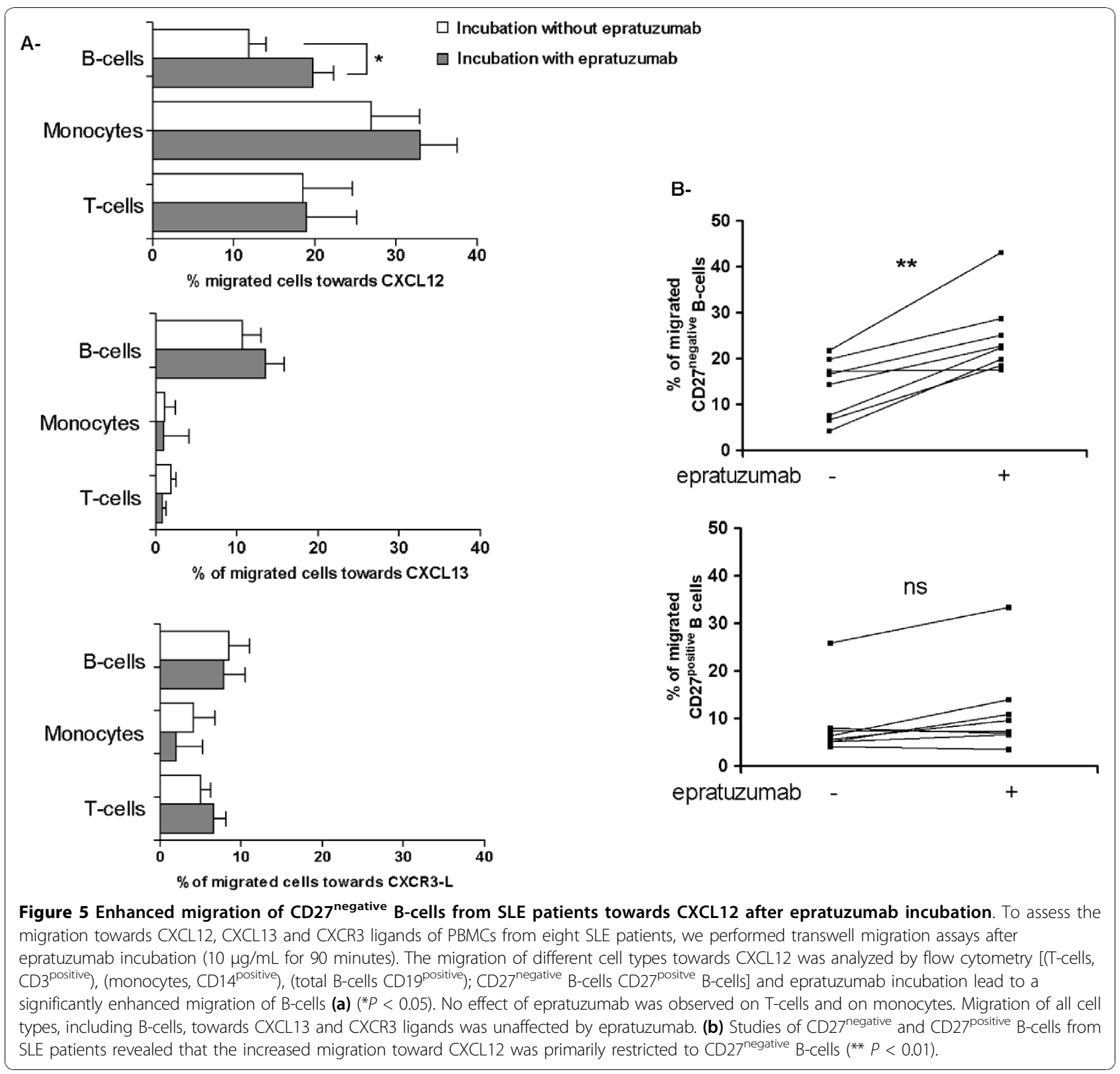

CD62L and $\beta 7$ integrin; 2) an associated increased $\beta 1$ integrin cell-surface expression; and 3) enhanced spontaneous migration and directed migration towards CXCL12. Since such changes were not induced to a large extent by epratuzumab on $\mathrm{CD} 27^{\text {positive }} \mathrm{B}$-cells, it appears plausible that these effects are linked to the higher CD22 surface expression on CD27 ${ }^{\text {negative }}$ B-cells.

\section{Differential binding of epratuzumab to PBMCs}

Epratuzumab was found to bind to the highest extent on CD27 $7^{\text {negative }}$ B-cells followed by CD27 ${ }^{\text {positive }}$ cells. The competition experiments demonstrated that this binding is specific via targeting CD22 and a role for Fc receptor binding could not be demonstrated. This difference between $\mathrm{CD} 27^{\text {negative }} \mathrm{B}$-cells and $\mathrm{CD} 27^{\text {positive }} \mathrm{B}$-cells can be explained by the higher expression of CD22 which we observed by FACS analysis and, according to the data base, CD22 mRNA is also more highly expressed on $\mathrm{CD} 27^{\text {negative }}$ naïve $\mathrm{B}$-cells and $\mathrm{CD} 27^{\text {negative }}$ transitional B-cells than on CD27 $7^{\text {positive }} \mathrm{B}$-cells (Platform ID: GPL570, accession no. [GEO:GSE17186]; Human B-cell subsets).

CD22 is not expressed on monocytes [4,6] but we did detect a small degree of epratuzumab binding to these cells consistent with the capacity of monocytes to mediate Fc receptor-dependent binding to antibodies $[28,29]$. 


\section{Modification of surface adhesion molecule expression by epratuzumab}

We observed a number of changes in adhesion molecule expression on the surface of B-cells under the influence of epratuzumab, such as a decrease of CD62L on CD27 $7^{\text {negative }} \mathrm{B}$-cells. Although the biological consequences of reduced CD62L expression remain to be delineated, it could potentially result in disturbed immune activation. Previous studies in CD62L-deficient mice reported that lymphocyte recruitment into inflammatory sites was inhibited significantly, whereas lymphocyte recruitment to the spleen was increased [30,31]. These results support the notion that reduced CD62L expression on B-cells by epratuzumab may disturb recruitment of B-cells to different sites of inflammation.

As with CD62L expression, epratuzumab incubation down-modulated $\beta 7$ integrin surface expression which was again seen primarily on CD27 $7^{\text {negative }}$ B-cells. The interaction of $\alpha 4 \beta 7$ integrin with its natural ligand, MAdCAM-1, is involved in the migration of immune cells to mucosal tissues. Whether there is a role for mucosal immune activation in SLE remains a matter of debate, although enhanced soluble CD14 likely related to LPS-dependent activation in gut-associated lymphoid tissues has been identified in the blood of SLE patients [32], consistent with persistent, enhanced activation of mucosal immunity.

Because of the apparent striking reductions of $\beta 7$ integrin expression on CD27 $7^{\text {negative }} \mathrm{B}$-cells after incubation with epratuzumab, and the known interdependence between $\beta 1$ and $\beta 7$ integrin expression on human T-cells which share the $\alpha 4$ integrin subunit [27], the regulation of $\beta 1$ integrin expression after epratuzumab incubation was investigated. Of importance, epratuzumab induced $\beta 1$ integrin expression on $C D 27^{\text {negative }}$ B-cells while its expression on the surface of $\mathrm{CD} 27^{\text {positive }}$ B-cells was already high at baseline and not substantially changed by epratuzumab. The data indicate that $\beta 1$ integrin and $\beta 7$ integrin expression could be regulated interdependently on $\mathrm{CD} 27^{\text {negative }} \mathrm{B}$-cells. In addition, binding to CD22 by epratuzumab provoked the activation of $\beta 1$ integrin and resulted in enhanced spontaneous migration of both $\mathrm{CD} 27^{\text {negative }}$ and $\mathrm{CD} 27^{\text {positive }}$ B-cells over fibronectin-coated membranes, independent of any chemokine. Thus, epratuzumab-enhanced $\beta 1$ integrin expression leads to functionally relevant effects on B-cells.

Overall, the modification of the adhesion molecule profile affected preferentially a fraction of $\mathrm{CD} 27^{\text {negative }}$ $\mathrm{B}$-cells. In this context, CD27 ${ }^{\text {negative }} \mathrm{B}$-cells comprise two main B-cell sub-populations, transitional B-cells and mature naïve $B$-cells [33]. However, we were unable to distinguish between these two subpopulations in our experiments. Since expansion of transitional B-cells in the circulation is correlated with clinical responses assessed by SLEDAI (Systemic Lupus Erythematosus Disease Activity Index) [33], further experiments are warranted to evaluate this hypothesis.

\section{Enhanced migration of CD27 $7^{\text {negative }}$ B-cells to CXCL12 in the presence of epratuzumab}

Studies conducted to investigate changes on B-cell migration showed that epratuzumab is able to enhance the migration of $\mathrm{CD} 27^{\text {negative }} \mathrm{B}$-cells across gradients of CXCL12 in vitro. This chemokine has been shown to be expressed by lymphoid organs [34,35] and inflamed kidneys [36,37] and, therefore, may account for enhanced emigration of $C D 27^{\text {negative }} B$-cells but not memory CD27 ${ }^{\text {positive }}$ B-cells from the peripheral blood observed clinically in SLE patients treated with epratuzumab [13]. Since epratuzumab binds preferentially to $\mathrm{CD} 27^{\text {negative }}$ B-cells, one could speculate that the enhanced migration of CD27 $7^{\text {negative }} \mathrm{B}$-cells is due to a stronger effect of CD22 expression on these cells.

Moreover, the bone marrow produces substantial amounts of CXCL12, and is able to attract antibodysecreting cells from the periphery [38]; it also employs CD22 and $\beta 1$ integrin for migration and retention of B-cells to this site $[6,11,12,21,23]$. If similar mechanisms apply also for other B cell subpopulations, such as $\mathrm{CD} 27^{\text {negative }}$ transitional or $\mathrm{CD} 27^{\text {negative }}$ naïve $\mathrm{B}$-cells, it is also possible that these cells become trapped in the bone marrow and cannot fully differentiate in secondary lymphoid organs.

Epratuzumab did not influence B-cell migration towards CXCL13 and CXCR3 ligands using PBMCs from SLE patients which argues that the migration changes observed with epratuzumab are not non-specific. However, we cannot rule out the possibility that the enhanced migration of CD2 $7^{\text {negative }}$ B-cells obtained from SLE patients may reflect the loss of migrating cells from the peripheral blood during active lupus. In this regard, it has been reported that levels of CXCL9, CXCL10 and CXCL11 correlate with lupus disease activity $[39,40]$. In addition, $\mathrm{CD} 4^{\text {positive }} \mathrm{CXCR} 3^{\text {positive }} \mathrm{T}$-cells have been found to be increased in the urine of patients with lupus nephritis, which may suggest involvement of this chemokine system [37].

With regard to the current study, a discussion of the interrelationship between CD22 modulation by epratuzumab and changes in adhesion molecule expression and migration is of importance. Interactions between intracellular signaling pathways may offer an explanation. In this context, Lyn is known to be the kinase responsible for phosphorylation of ITIMs on CD22 [41] and it has been reported that Lyn is of critical importance in SLE with lower expression of Lyn being typical for SLE patients $[42,43]$. In addition, Lyn is closely 
related to Syk (Spleen tyrosine kinase) which is involved in BCR signaling, but also in the regulation of integrin activation [44]. Moreover, recent work indicates that Syk is involved in CXCL12- and $\alpha 4 \beta 1$ integrin-induced signaling in chronic lymphocytic leukemia [45]. Further investigation of CD22-Lyn-Syk interactions could lead to a better understanding of the precise mechanisms by which CD22 regulates cell adhesion and migration pathways in B cells.

\section{Conclusions}

This study demonstrates for the first time that the humanized anti-CD22 mAb, epratuzumab, displays a substantially higher degree of binding to CD22 on $\mathrm{CD} 27^{\text {negative }} \mathrm{B}$-cells resulting in functional effects such as enhanced migration towards CXCL12 and modification of adhesion molecule cell surface expression (down-regulation of the expression of CD62L and $\beta 7$ integrin and up-regulation of $\beta 1$ integrin). Collectively, the data suggest that epratuzumab could disturb trafficking of CD27 $7^{\text {negative }} \mathrm{B}$-cells, which provides an insight into the potential mechanism of action of this antibody in SLE.

\begin{abstract}
Abbreviations
ACR: American College of Rheumatology; ADCC: antibody-dependent cellular cytotoxicity; ASC: antibody-secreting cells; BCR: B-cell antigen receptor; BILAG: British Isles Lupus Assessment Group; SLEDAl: Systemic Lupus Erythematosus Disease Activity Index; BL-CAM: B-lymphocyte cell adhesion molecule; BSA: bovine serum albumin; CDC: complement-dependent cytotoxicity; Cy5: cyanin 5; DAPI: 4',6-diamidino-2-phenylindol; F(ab')2: fragments antigen binding 2; FACS: fluorescence activated cell sorting; FITC fluorescein isothiocyanate; H7-APC: H7-allophycocyanin; ITIMs: immunoreceptor tyrosine-based inhibitory motifs; mAb: monoclonal antibody; MFI: mean fluorescence intensity; MIG: monokine induced by gamma interferon; PB: pacific blue; PBMCs: peripheral blood mononuclear cells; PBS: phosphate-buffered saline; PE: phycoerythrin; PE-Cy7: phycoerythrin-cyanin 7; PerCP: peridin chlorophyll protein; Siglec-2: Sialic acid-binding Ig-like lectin 2; SLE: systemic lupus erythematosus; SyK: spleen tyrosine kinase; VCAM-1: vascular cell adhesion molecule-1.
\end{abstract}

\section{Acknowledgements}

This study was supported by Sonderforschungsbereich 650 and DFG491/7-1.

\section{Author details}

${ }^{1}$ Charite - Universitätsmedizin Berlin, CC12 Dept. Medicine/Rheumatology and Clinical Immunology, Chariteplatz 1, Berlin 10117, Germany. ${ }^{2}$ Deutsches Rheumaforschungszentrum (DRFZ), Chariteplatz 1, Berlin 10117, Germany. ${ }^{3}$ Center for Molecular Medicine and Immunology, Garden State Cancer Center, 520 Belleville Ave., Belleville, NJ 07109, USA

\section{Authors' contributions}

$\mathrm{DB}, \mathrm{CD}, \mathrm{KR}, \mathrm{DF}, \mathrm{AHo}$ carried out experimental work in different areas. AHa, CG and AHo discussed the data at several stages and worked on the manuscript. CD, DMG, HM, and TD designed the study, analyzed data and wrote the manuscript. All authors read and approved the final manuscript.

\section{Competing interests}

TD has received research support from Immunomedics. This study was funded in part by UCB Inc; DMG has a management role and equity in Immunomedics, Inc. All other authors declare that they do not have any competing interests.
Received: 15 December 2009 Accepted: 4 November 2010

Published: 4 November 2010

\section{References}

1. Anolik JH: B cell biology and dysfunction in SLE. Bull NYU Hosp Jt Dis 2007, 65:182-186.

2. Dorner T, Kaufmann J, Wegener WA, Teoh N, Goldenberg DM, Burmester GR: Initial clinical trial of epratuzumab (humanized anti-CD22 antibody) for immunotherapy of systemic lupus erythematosus. Arthritis Res Ther 2006, 8:R74.

3. Kalunian K, Wallace D, Petri M, Houssiau F, Pike M, Kilgallen B, Barry A, Gordon C: Bilag-measured improvement in moderately and severely affected body systems in patients with systemic lupus erythematosus (sle) by epratuzumab: results from emblem ${ }^{\mathrm{TM}}$, a phase iib study. EULAR Meeting 2010, Roma 2010, SAT0197.

4. Engel P, Nojima Y, Rothstein D, Zhou LJ, Wilson GL, Kehrl JH, Tedder TF: The same epitope on CD22 of B lymphocytes mediates the adhesion of erythrocytes, T and B lymphocytes, neutrophils, and monocytes. J Immunol 1993, 150:4719-4732.

5. Schwartz-Albiez R, Dorken B, Monner DA, Moldenhauer G: CD22 antigen: biosynthesis, glycosylation and surface expression of a $B$ lymphocyte protein involved in B cell activation and adhesion. Int Immunol 1991, 3:623-633.

6. Dorken B, Moldenhauer G, Pezzutto A, Schwartz R, Feller A, Kiesel S, Nadler LM: HD39 (B3), a $B$ lineage-restricted antigen whose cell surface expression is limited to resting and activated human B lymphocytes. J Immunol 1986, 136:4470-4479.

7. Stoddart A, Ray RJ, Paige CJ: Analysis of murine CD22 during B cell development: CD22 is expressed on B cell progenitors prior to lgM. Int Immunol 1997, 9:1571-1579.

8. Sathish JG, Walters J, Luo JC, Johnson KG, Leroy FG, Brennan P, Kim KP, Gygi SP, Neel BG, Matthews RJ: CD22 is a functional ligand for SH2 domain-containing protein-tyrosine phosphatase-1 in primary T cells. J Biol Chem 2004, 279:47783-47791.

9. Doody GM, Justement LB, Delibrias CC, Matthews RJ, Lin J, Thomas ML, Fearon DT: A role in B cell activation for CD22 and the protein tyrosine phosphatase SHP. Science 1995, 269:242-244.

10. Walker JA, Smith KG: CD22: an inhibitory enigma. Immunology 2008, 123:314-325.

11. Nitschke L, Floyd H, Ferguson DJ, Crocker PR: Identification of CD22 ligands on bone marrow sinusoidal endothelium implicated in CD22dependent homing of recirculating B cells. J Exp Med 1999, 189:1513-1518.

12. Floyd H, Nitschke L, Crocker PR: A novel subset of murine B cells that expresses unmasked forms of $\mathrm{CD} 22$ is enriched in the bone marrow: implications for B-cell homing to the bone marrow. Immunology 2000, 101:342-347.

13. Jacobi AM, Goldenberg DM, Hiepe F, Radbruch A, Burmester GR, Dorner T: Differential effects of epratuzumab on peripheral blood $B$ cells of patients with systemic lupus erythematosus versus normal controls. Ann Rheum Dis 2008, 67:450-457.

14. Carnahan J, Stein R, Qu Z, Hess K, Cesano A, Hansen HJ, Goldenberg DM: Epratuzumab, a CD22-targeting recombinant humanized antibody with a different mode of action from rituximab. Mol Immunol 2007, 44:1331-1341.

15. Weitzman J, Betancur M, Boissel L, Rabinowitz AP, Klein A, Klingemann H: Variable Contribution of Monoclonal Antibodies to ADCC in patients with chronic lymphocytic leukemia. Leuk Lymphoma 2009, 50:1361-1368.

16. Carnahan J, Wang P, Kendall R, Chen C, Hu S, Boone T, Juan T, Talvenheimo J, Montestruque S, Sun J, Elliott G, Thomas J, Ferbas J, Kern B, Briddell R, Leonard JP, Cesano A: Epratuzumab, a humanized monoclonal antibody targeting CD22: characterization of in vitro properties. Clin Cancer Res 2003, 9:39825-3990S.

17. Stein R, Belisle E, Hansen HJ, Goldenberg DM: Epitope specificity of the anti-(B cell lymphoma) monoclonal antibody, LL2. Cancer Immunol Immunother 1993, 37:293-298.

18. Shaw SK, Brenner MB: The beta 7 integrins in mucosal homing and retention. Semin Immunol 1995, 7:335-342

19. Rainer TH: L-selectin in health and disease. Resuscitation 2002, 52:127-141. 
20. Wagner N, Lohler J, Kunkel EJ, Ley K, Leung E, Krissansen G, Rajewsky K, Muller W: Critical role for beta7 integrins in formation of the gutassociated lymphoid tissue. Nature 1996, 382:366-370.

21. Koni PA, Joshi SK, Temann UA, Olson D, Burkly L, Flavell RA: Conditional vascular cell adhesion molecule 1 deletion in mice: impaired lymphocyte migration to bone marrow. J Exp Med 2001, 193:741-754.

22. Brakebusch C, Fillatreau S, Potocnik AJ, Bungartz G, Wilhelm P, Svensson M, Kearney $P$, Korner $H$, Gray D, Fassler R: Beta1 integrin is not essential for hematopoiesis but is necessary for the T cell-dependent IgM antibody response. Immunity 2002, 16:465-477.

23. Potocnik AJ, Brakebusch C, Fassler R: Fetal and adult hematopoietic stem cells require beta1 integrin function for colonizing fetal liver, spleen, and bone marrow. Immunity 2000, 12:653-663.

24. Tan EM, Cohen AS, Fries JF, Masi AT, McShane DJ, Rothfield NF, Schaller JG, Talal N, Winchester RJ: The 1982 revised criteria for the classification of systemic lupus erythematosus. Arthritis Rheum 1982, 25:1271-1277.

25. Argraves WS, Suzuki S, Arai H, Thompson K, Pierschbacher MD, Ruoslahti E: Amino acid sequence of the human fibronectin receptor. J Cell Biol 1987, 105:1183-1190.

26. Mei HE, Yoshida T, Sime W, Hiepe F, Thiele K, Manz RA, Radbruch A, Dorner T: Blood-borne human plasma cells in steady state are derived from mucosal immune responses. Blood 2009, 113:2461-2469.

27. DeNucci CC, Pagan AJ, Mitchell JS, Shimizu Y: Control of alpha4beta7 integrin expression and CD4 T cell homing by the beta1 integrin subunit. J Immunol 2010, 184:2458-2467.

28. Kavai M, Szegedi G: Immune complex clearance by monocytes and macrophages in systemic lupus erythematosus. Autoimmun Rev 2007, 6:497-502.

29. Woof JM, Nik Jaafar Ml, Jefferis R, Burton DR: The monocyte binding domain(s) on human immunoglobulin G. Mol Immunol 1984, 21:523-527.

30. Arbones ML, Ord DC, Ley K, Ratech H, Maynard-Curry C, Otten G, Capon DJ Tedder TF: Lymphocyte homing and leukocyte rolling and migration are impaired in L-selectin-deficient mice. Immunity 1994, 1:247-260.

31. Tedder TF, Steeber DA, Pizcueta P: L-selectin-deficient mice have impaired leukocyte recruitment into inflammatory sites. J Exp Med 1995, 181:2259-2264.

32. Egerer K, Feist E, Rohr U, Pruss A, Burmester GR, Dorner T: Increased serum soluble CD14, ICAM-1 and E-selectin correlate with disease activity and prognosis in systemic lupus erythematosus. Lupus 2000, 9:614-621.

33. Sims GP, Ettinger $R$, Shirota $Y$, Yarboro $C H$, Illei GG, Lipsky PE: Identification and characterization of circulating human transitional B cells. Blood 2005, 105:4390-4398.

34. Bleul CC, Fuhlbrigge RC, Casasnovas JM, Aiuti A, Springer TA: A highly efficacious lymphocyte chemoattractant, stromal cell-derived factor 1 (SDF-1). J Exp Med 1996, 184:1101-1109.

35. Forster R, Mattis AE, Kremmer E, Wolf E, Brem G, Lipp M: A putative chemokine receptor, BLR1, directs $B$ cell migration to defined lymphoid organs and specific anatomic compartments of the spleen. Cell 1996, 87:1037-1047.

36. Cassese G, Lindenau S, de Boer B, Arce S, Hauser A, Riemekasten G, Berek C Hiepe F, Krenn V, Radbruch A, Manz RA: Inflamed kidneys of NZB/W mice are a major site for the homeostasis of plasma cells. Eur J Immunol 2001, 31:2726-2732.

37. Enghard $P$, Humrich $J Y$, Rudolph $B$, Rosenberger $S$, Biesen $R$, Kuhn $A$, Manz R, Hiepe F, Radbruch A, Burmester GR, Riemekasten G: CXCR3+CD4+ $T$ cells are enriched in inflamed kidneys and urine and provide a new biomarker for acute nephritis flares in systemic lupus erythematosus patients. Arthritis Rheum 2009, 60:199-206.

38. Cyster JG: Homing of antibody secreting cells. Immunol Rev 2003, 194:48-60.

39. Narumi S, Takeuchi T, Kobayashi $Y$, Konishi K: Serum levels of ifn-inducible PROTEIN-10 relating to the activity of systemic lupus erythematosus. Cytokine 2000, 12:1561-1565.

40. Bauer JW, Baechler EC, Petri M, Batliwalla FM, Crawford D, Ortmann WA, Espe KJ, Li W, Patel DD, Gregersen PK, Behrens TW: Elevated serum levels of interferon-regulated chemokines are biomarkers for active human systemic lupus erythematosus. PLoS Med 2006, 3:e491.

41. Flores-Borja F, Kabouridis PS, Jury EC, Isenberg DA, Mageed RA: Decreased Lyn expression and translocation to lipid raft signaling domains in $B$ lymphocytes from patients with systemic lupus erythematosus. Arthritis Rheum 2005, 52:3955-3965.
42. Liossis SN, Solomou EE, Dimopoulos MA, Panayiotidis P, Mavrikakis MM, Sfikakis PP: B-cell kinase lyn deficiency in patients with systemic lupus erythematosus. J Investig Med 2001, 49:157-165.

43. Taher TE, Parikh K, Flores-Borja F, Mletzko S, Isenberg DA, Peppelenbosch MP, Mageed RA: Protein phosphorylation and kinome profiling reveal altered regulation of multiple signalling pathways in $B$ lymphocytes from patients with systemic lupus erythematosus. Arthritis Rheum 2010.

44. Mocsai A, Ruland J, Tybulewicz VL: The SYK tyrosine kinase: a crucial player in diverse biological functions. Nat Rev Immunol 2010, 10:387-402

45. Buchner M, Baer C, Prinz G, Dierks C, Burger M, Zenz T, Stilgenbauer S, Jumaa $H$, Veelken $H$, Zirlik K: Spleen tyrosine kinase inhibition prevents chemokine- and integrin-mediated stromal protective effects in chronic lymphocytic leukemia. Blood 2010, 115:4497-4506.

doi:10.1186/ar3179

Cite this article as: Daridon et al:: Epratuzumab targeting of CD22 affects adhesion molecule expression and migration of B-cells in systemic lupus erythematosus. Arthritis Research \& Therapy 2010 12:R204

\section{Submit your next manuscript to BioMed Central and take full advantage of:}

- Convenient online submission

- Thorough peer review

- No space constraints or color figure charges

- Immediate publication on acceptance

- Inclusion in PubMed, CAS, Scopus and Google Scholar

- Research which is freely available for redistribution
Ciomed Central 